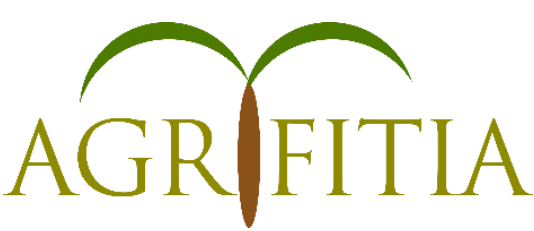

Journal Agrifitia. Vol. 1, No. 2 September 2021

Journal home page: https://jurnal.instiperjogja.ac.id/index.php/AFT

\title{
FAKTOR - FAKTOR YANG MEMPENGARUHI WANITA BEKERJA SEBAGAI TENAGA KERJA PERUSAHAAN DI PTPN IV PABATU SUMATERA UTARA
}

\author{
Lasmaria Sipahutar ${ }^{1}$, Ismiasih ${ }^{1}$, Siwi Isiana Dinarti', Danang Manumono ${ }^{1}$ \\ ${ }^{1}$ Jurusan Ekonomi Pertanian, Fakultas Pertanian, INSTIPER Yogyakarta \\ *e-mail: ismiasih2017@gmail.com
}

\begin{abstract}
Women in society have a dual role, one of which is as a companion to the head of the family in earning a living. This study aims to : 1) find out what factors influence women to work as female workers in the company, 2) find out the economic condition of the family of female workers who work at PTPN Pabatu, North Sumatera. The research method used descriptive quantitative method. Descripte method is a method that is carried out by describing or describing a state of the subject under study. The factors that influence women working in companies are analyzed using the Multiple Linear Regression method. The location of the research was PTPN IV Pabatu, Tebing Tinggi District, Serdang Bedagai Regency, North Sumatera. The study was conducted from March to April 2021. The method used in determining the sample was the pusposive sampling method by taking a total of 30 samples. The results showed that the spouse's income, number of dependents and self-development had a significant effect on women working as company workers at PTPN IV Pabatu. The spouse's income has a negative effect on working as workers in the company, while the number of dependents and self development have a positive effect on the desire of women to work as company workers. The economic conditions of the families of women working at PTPN IV Pabatu fall into middle to lower category.
\end{abstract}

Keywords : female labor, Multiple Linear Regression 


\section{PENDAHULUAN}

Banyak orang yang berfikir bahwa wanita selalu dikaitkan dengan mengurus rumah tangga, anak, dan suami. Perbedaan fisik dan psikis antara laki-laki dan perempuan menimbulkan perbedaan fungsi antara keduanya. Perempuan memiliki peran ganda, antara lain sebagai seorang ibu, yang bertugas melahirkan anak, sehingga menimbulkan konsekuensi untuk merawat, mengasuh, menyusui, dan memberikan kasih sayang, sementara itu laki-laki berfungsi sebagai pencari nafkah dikarenakan mempunyai kondisi fisik yang kuat. Seorang wanita adakalanya dituntut untuk membantu suami atau kepala keluarga dalam mencari nafkah untuk mencukupi kebutuhan hariannya. Pembagian fungsi tersebut pada akhirnya menumbuhkan pembagian kerja secara generalisasi yang menonjol yaitu ditempatkannya wanita pada pekerjaan domestik sedangkan laki-laki sebagai pencari nafkah utama.

Perusahaan kelapa sawit secara umum tidak hanya melibatkan tenaga kerja laki-laki, namun tenaga kerja wanita juga memiliki peran dalam membantu perusahaan untuk mencapai tujuannya. Di perkebunan kelapa sawit PTPN IV Pabatu, tenaga kerja wanita dibutuhkan di dalam pekerjaan perusahan yang membutuhkan ketelitian. Meskipun lingkungan di perusahaan kurang mendukung namun minat wanita bekerja diperusahaan tetap ada. Hal ini dikarenakan tuntutan kebutuhan keluarga yang semakin meningkat sehingga mengharuskan kaum wanita atau istri harus ikut serta dalam mencari nafkah keluarga. Di PTPN IV Pabatu, umumnya wanita dipekerjakan di bagian perawatan tanaman, membersihkan halaman kantor maupun tempat lain yang ada di perusahaan, di bagian administrasi dan di lapangan sebagai tenaga pengutip berondolan, proses pemupukan serta kegiatan lain yang mampu dikerjakan oleh wanita. Wantini dan Kurniati (2013) dari hasil penelitian menyebutkan faktor-faktor yang mempengaruhi motivasi wanita bekerja sebagai buruh pabrik adalah karena faktor ekonomi. Penelitian lain dilakukan oleh Putu, Nilakusmawati, dan Susilawati (2012) yang menyimpulkan bahwa faktor yang mempengaruhi wanita bekerja adalah tingkat pendidikan terakhir wanita dan penghasilan suami. Sementara penelitian Hasanah, Suswandi, dan Yunitasari (2019) menyebutkan bahwa jumlah tanggungan tidak mempengaruhi minat wanita untuk bekerja. Nugraehi, S (2012) menyebutkan kegiatan wanita dalam membantu kebutuhan rumah tangga di wujudkan dalam rumah tangga, bidang ekonomi, dan masyarakat. 


\section{METODOLOGI}

Penelitian ini menggunakan metode deskriptif-kuantitatif, metode deskriptif adalah metode yang dilakukan dengan cara mendeskripsikan atau menggambarkan suatu keadaan subjek yang diteliti. Menurut Sugiyono (2016) metode deskriptif adalah metode penelitian yang menggambarkan atau menganalisis hasil penelitian tetapi tidak digunakan untuk membuat kesimpulan yang lebih luas. Penelitian deskriptif merupakan penelitian dengan mendeskripsikan suatu peristiwa yang terjadi pada saat sekarang. Penelitian kuantitatif adalah suatu proses menemukan pengetahuan dengan menggunakan data berupa angka sebagai alat untuk menganalisis keterangan mengenai sesuatu yang ingin diketahui. Bentuk penelitian deskriptif kuantitatif yang dilakukan peneliti dalam permasalahan ini dengan melihat situasi dan kondisi secara alami dari responden yang ditemui untuk memperoleh kebenaran dari lapangan dan menganalisis data dan hal yang berhubungan dengan angka - angka atau model perhitungan yang digunakan untuk menganalisis faktor - faktor yang mempengaruhi wanita bekerja sebagai tenaga kerja perusahaan di PTPN IV Pabatu.

Penentuan lokasi penelitian dilakukan secara studi kasus. Menurut Sugiyono (2016) studi kasus adalah metode yang bertujuan untuk mempelajari dan menyelidiki suatu kejadian atau fenomena mengenai seorang individu sebagai objek penelitian. Penelitian dilakukan di PTPN.IV Pabatu Kecamatan Tebing Tinggi, Kabupaten Serdang Bedagai, Sumatera Utara. Penelitian dilaksanakan pada bulan maret sampai april tahun 2021.

Metode yang digunakan dalam penelitian ini adalah metode purposive sampling, menurut Sugiono (2016) metode penentuan sampel purposive adalah teknik pengambilan sampel dengan menentukan kriteria - kriteria tertentu. Jumlah sampel yang digunakan pada penelitian ini adalah sebanyak 30 sampel, yang diantara 30 sampel kriteria yang dipilih untuk menjadi sampel adalah 10 sampel untuk tenaga kerja buruh, 10 sampel untuk tenaga kerja umur 30 tahunan dan 10 sampel untuk usia 40 tahun keatas.

Tujuan pertama di analisis dengan menggunakan metode analisis regresi berganda yaitu model regresi linear dengan melibatkan lebih dari satu variable bebas atau predictor.Dalam bahasa inggris, istilah ini disebut dengan multiple linear regression. Bentuk umum persamaan regresi linear berganda dapat dituliskan sebagai berikut:

$$
Y=a+b_{1} x_{1}+b_{2} x_{2}+\ldots .+b_{n} x_{n}+e
$$

$\begin{array}{ll}\text { Keterangan } & : \\ Y= & \text { Variabel terikat } \\ X= & \text { Variabel bebas } \\ \alpha= & \text { Konstanta } \\ b= & \text { Koefisien estimate } \\ e= & \text { error }\end{array}$


Faktor-faktor yang mempengaruhi wanita bekerha sebagai tenaga kerja di perusahaan dianalisis dengan menggunakan analisis linear berganda, dengan formulasi persamaan sebagai berikut :

$Y=\alpha+b_{1} X_{1}+b_{2} X_{2}+b_{3} X_{3}+b_{4} X_{4}+b_{5} X_{5}+b_{6} X_{6}+b_{7} X_{7}+e$

Keterangan

$\mathrm{Y}$ : Alasan wanita bekerja ( \% )

$\mathrm{X}_{1}$ : Usia (Tahun)

$\mathrm{X}_{2}$ : Pendidikan (Tahun)

$\mathrm{X}_{3}$ : Penghasilan pasangan (Rp/bulan)

$\mathrm{X}_{4}$ : Jumlah tanggungan (Orang)

$\mathrm{X}_{5}$ : Pengeluaran rumah tangga

(Rp/bulan)

$\mathrm{X}_{6}$ : Mengembangkan diri (5 : sangat setuju, 4:setuju, 3:ragu,2:kurang setuju, 1:tidak setuju)

$\mathrm{X}_{7}$ : Mengisi waktu luang (5: sangat setuju, 4 : setuju, 3 : ragu, 2 : kurang setuju, 1 : tidak setuju)

$\alpha$ : Konstanta

$\mathrm{b}:$ Koefisien parameter

e : error

Tujuan ke dua dianalisis dengan metode deskriptif, yaitu prosedur pemecahan masalah yang diselidiki dengan menggambarkan keadaan subjek atau objek dalam penelitian dapat berupa orang, lembaga, masyarakat dan yang lainnya berdasarkan fakta-fakta yang tampak. Penelitian dengan metode ini diharapkan dapat menjelaskan suatu situasi yang hendak diteliti sehingga lebih memperkuat analisa peneliti dalam membuat suatu kesimpulan dan menilai sifat dari kondisi yang tampak. 


\section{HASIL DAN PEMBAHASAN}

A. Faktor yang mempengaruhi wanita bekerja sebagai tenaga kerja perusahaan

1. Uji regresi linear berganda

Analisis regresi linear berganda adalah hubungan secara linear antara dua atau lebih variabel independen dengan variabel dependen.

a. Uji t

Jika nilai signifikansi $<0,05$ maka artinya variabel $X$ berpengaruh terhadap variabel $Y$, untuk mengetahui hasilnya maka dapat dilihat pada tabel dibawah ini.

Tabel 1. Tabel uji t

\begin{tabular}{|c|c|c|c|c|c|c|c|c|}
\hline \multirow{2}{*}{\multicolumn{2}{|c|}{ Model }} & \multicolumn{2}{|c|}{$\begin{array}{c}\text { Unstandardized } \\
\text { Coefficients }\end{array}$} & \multirow{2}{*}{$\begin{array}{c}\text { Standardized } \\
\text { Coefficients } \\
\text { Beta } \\
\end{array}$} & \multirow[t]{2}{*}{$\mathrm{t}$} & \multirow[t]{2}{*}{ Sig. } & \multicolumn{2}{|c|}{$\begin{array}{c}\text { Collinearity } \\
\text { Statistics }\end{array}$} \\
\hline & & $\mathrm{B}$ & Std. Error & & & & Tolerance & VIF \\
\hline \multirow{8}{*}{1} & (Constant) & 2.496 & .357 & & 6.987 & .000 & & \\
\hline & $\times 1$ & .007 & .008 & .174 & .964 & .346 & .462 & 2.166 \\
\hline & $\times 2$ & -.014 & .015 & -.121 & -.929 & .363 & .890 & 1.123 \\
\hline & $\times 3$ & $-1.498 E-007$ & .000 & -.641 & -2.265 & .034 & .187 & 5.340 \\
\hline & $\times 4$ & .154 & .064 & .391 & 2.414 & .025 & .573 & 1.744 \\
\hline & $\times 5$ & $-2.118 \mathrm{E}-008$ & .000 & -.086 & -.283 & .780 & .161 & 6.199 \\
\hline & $\times 6$ & .202 & .066 & .552 & 3.071 & .006 & .464 & 2.154 \\
\hline & $\times 7$ & .033 & .067 & .092 & .499 & .622 & .446 & 2.243 \\
\hline
\end{tabular}

a. Dependent Variable: $Y$

Berdasarkan hasil pengolahan data analisis regresi linear berganda pada tabel 1 , maka diperoleh hasil persamaan regresi sebagai berikut:

$Y=2.496+0,007 X 1-0,14 X 2-1,498 X 3+0,154 X 4-2,118 X 5+0,0202 X 6+0,033$ X7

Keterangan :

Y : Alasan wanita bekerja

X1 : Usia

X2 : Pendidikan

X3 : Penghasilan pasangan

X4 : Jumlah tanggungan

X5 : Pengeluaran rumah tangga

X6 : Mengembangkan diri

X7 : Mengisi waktu luang 
Dari hasil output yang diperoleh maka didapat hasil bahwa usia (X1), pendidikan (X2), pengeluaran rumah tangga (X5), dan mengisi waktu luang(X7) tidak berpengaruh signifikan karena nilai $\alpha>0,05$, sedangkan variabel penghasilan pasangan (X3), jumlah tanggungan (X4), dan mengembangkan diri (X6) berpengaruh signifikan karena nilai $\alpha<0,05$.

Varibel penghasilan pasangan (X3) memiliki koefisien bertanda negative artinya kontribusi variabel penghasilan pasangan ini memberikan pengaruh negatif terhadap faktor yang mempengaruhi wanita bekerja di perusahaan yang berarti semakin tinggi penghasilan pasangan maka tingkat keinginan wanita untuk bekerja akan semakin kecil atau setiap kenaikan penghasilan naik sebesar Rp.1 maka akan turun keinginan wanita bekerja diperusahaan sebesar $-1,498$.

Koefisien variabel jumlah tanggungan (X4) bertanda positif artinya variabel jumlah tanggungan adalah faktor yang mendukung wanita untuk bekerja sebagai tenaga kerja di perusahaan. Artinya semakin banyak jumlah tanggungan maka keinginan wanita untuk bekerja akan semakin tinggi atau setiap kenaikan jumlah tanggungan 1 orang maka keinginan wanita untuk bekerja akan meningkat sebesar 0,154 . Koefisien variable mengembangkan diri (X6) bertanda positif artinya variabel ini berpengaruh positif terhadap Wanita untuk bekerja sebagai tenaga kerja perusahaan. Artinya setiap ada keinginan wanita bekerja untuk mengembangkan diri naik 1 tingkat maka keinginan wanita untuk bekerja akan naik sebesar 0,202 .

b. Uji F

Uji F dapat dilakukan dengan membendingkan $\mathrm{F}$ hitung dengan $\mathrm{F}$ tabel, jika $\mathrm{F}$ hitung > $\mathrm{F}$ tabel maka artinya variabel dependen $(\mathrm{X})$ secara simultan berpengaruh terhadap variabel independen $(\mathrm{Y})$, atau bisa dilihat dalam kolom signifikansi pada tabel anova jika nilai signifikansi < 0,05 maka dapat disimpulkan bahwa hipotesis diterima, untuk lebih jelasnya maka dapat dilihat pada tabel 2 .

Tabel 2. Tabel Uji F

ANOVA $^{a}$

\begin{tabular}{|l|r|r|r|r|l|}
\hline Model & Sum of Squares & df & Mean Square & F & Sig. \\
\hline Regression & 2.145 & 7 & .306 & 6.366 & $.000^{\mathrm{b}}$ \\
1 Residual & 1.059 & 22 & .048 & & \\
Total & 3.204 & 29 & & & \\
\hline
\end{tabular}
a. Dependent Variable: $Y$
b. Predictors: (Constant), X7, X4, X2, X1, X3, X6, X5 
Dari hasil yang diperoleh maka variabel dependen secara simultan berpengaruh terhadap variabel dependen dengan nilai sig. 0,000<0,05. Pengujian hipotesis dengan membandingkan nilai $f$ hitung dan $f$ tabel. Dari tabel dapat diketahui bahwa nilai $f$ hitung adalah 6,366 dan $f$ tabel adalah 2,464 yang berarti nilai $f$ hitung $>f$ tabel. Sehingga dapat disimpulkan bahwa usia, pendidikan, penghasilan pasangan, jumlah tanggungan, pengeluaran rumah tangga, mengembangkan diri, dan mengisi waku luang berpengaruh terhadap faktor - yang mempengaruhi wania bekerja sebagai tenaga kerja perusahaan,. Dari hasil ini maka dapa disimpulkan bahwa hipotesis diterima atau dengan kata lain bahwa variabel bebas berpengaruh terhadap variabel terikat.

c. Uji R Square

Makna koefisien determinasi ( $R$ Square) dalam analisis regresi berganda bermakna sebagai sumbangan pengaruh yang diberikan oleh variabel independen terhadap variabel dependen. Untuk lebih jelasnya maka dapat dilihat pada tabel 3 berikut ini.

Tabel 3. Tabel R Square

Model Summary

\begin{tabular}{|l|l|r|r|r|}
\hline Model & $\mathrm{R}$ & $\mathrm{R}$ Square & Adjusted R Square & Std. Error of the Estimate \\
\hline 1 & $.818^{\mathrm{a}}$ & .669 & .564 & .219397 \\
\hline
\end{tabular}

a. Predictors: (Constant), X7, X4, X2, X1, X3, X6, X5

Berdasarkan tabel 3. Dapat diketahui nilai koefisien determinasi atau $\mathrm{R}$ Square adalah sebesar 0,669 atau sama dengan 66,9\%. Artinya bahwa variabel independen secara simultan berpengaruh terhadap variabel dependen sebesar $66,9 \%$ sedangkan sisanya sebesar $33,1 \%$ dipengaruhi oleh variabel lain diluar model persamaan regresi atau diluar variabel yang diteliti.

\section{Kondisi perekonomian}

1. Kondisi rumah

Kondisi rumah adalah indikator yang digunakan untuk mengetahui bagaimana kondisi tempat tinggal responden seperti bagaimana keadaan atap, lantai rumah, dinding dan kondisi lainnya, untuk lebih jelasnya maka dapat dilihat lihat pada tabel 4.

Tabel 4. Tabel kondisi rumah

\begin{tabular}{ccc}
\hline Kategori & Frekuensi ( orang ) & Persentase (\%) \\
\hline Sangat layak & 6 & 20,00 \\
layak & 15 & 50,00 \\
Cukup layak & 9 & 30,00 \\
Kurang layak & 0 & 0 \\
\hline Jumlah & 30 & $100 \%$
\end{tabular}


Dari tabel 4. dapat disimpulkan bahwa untuk kondisi rumah terbanyak adalah kategori layak sebanyak $50 \%$ dari responden yang ditemui, kategori layak menurut peneliti adalah dilihat dari kondisi bangunan, kebersihan, dan kodisi halaman, untuk kedaan ini dapat dipengaruhi oleh pendapatan keluarga, pangkat atau kedudukan yang dimiliki oleh responden maupun pasangan responden yang bekerja di perusahaan karna perusahaan sendiri telah menyediakan rumah untuk karyawan yang bekerja di perusahaan dan kondisi rumah yang diberikan juga berbeda tergantung dari pangkat atau jabatan dari karyawan dan hampir semua rumah menambahkan bangunan lain untuk memperluas atau memperindah kondisi rumah yang diberikan (karyawan setempat biasa menjulukinya dapur atau teras tempel) dengan kondisi rumah yang sederhana dan hampir mirip semua namun ada bebarapa responden yang tidak tinggal dirumah yang diberikan oleh perusahaan melainkan dirumah milik sendiri.

2. Pemenuhuhan gizi 4 sehat

Pemenuhan gizi adalah indikator yang digunakan untuk mengetahui apakah kebutuhan gizi 4 sehat didalam keluarga responden sudah terpenuhi atau tidak, untuk lebih jelasnya maka dapat dilihat pada tabel 5 .

Tabel 5. Pemenuhan gizi 4 sehat

\begin{tabular}{ccc}
\hline Kategori & Frekuensi (orang) & Persentase (\%) \\
\hline Sangat terpenuhi & 7 & 23,33 \\
Terpenuhi & 12 & 40,00 \\
Cukup terpenuhi & 9 & 30,00 \\
Kurang terpenuhi & 2 & 6,66 \\
\hline Jumlah & 30 & $100 \%$
\end{tabular}

Sumber: Analisis data primer 2021

Dari table 5 dapat disimpulkan bahwa ada sebanyak 12 orang dengan pemenuhan gizi 4 sehat kategori terpenuhi, cukup terpenuhi sebanyak 9 orang, sangat terpenuhi sebanyak 7 orang dan kurang terpenuhi sebanyak 2 orang.Kondisi ini tentu sangat dipengaruhi oleh pendapatan keluarga karna semakin banyak pendapatan keluarga maka keinginan untuk pemenuhan gizi didalam keluarga akan semakin tinggi.

3. Kendaraan bermesin

Kendaraan bermesin adalah indikator yang digunakan unttuk mengetahui kondisi perekonomian keluarga melalui apa kendaraan yang dimiliki keluarga responden, untuk lebih jelas dapat dilihat pada tabel 6. 
Tabel 6. Kendaraan bermesin

\begin{tabular}{ccc}
\hline Kategori & Frekuensi (orang) & Persentase (\%) \\
\hline $\begin{array}{c}\text { Mempunyai mobil dan } \\
\text { sepeda motor }\end{array}$ & 4 & 13,33 \\
$\begin{array}{c}\text { Mempunyai sepeda motor } \\
\text { Jumlah }\end{array}$ & 26 & 86,66 \\
\hline
\end{tabular}

Sumber:Analisis data primer 2021

Dari tabel diatas dapat diketahui bahwa dari 30 responden kategori untuk kepemilikan kendaraan bermotor terbanyak adalah yang hanya memiliki sepeda motor yaitu sebanyak 24 orang dan hanya 4 orang yang memiliki sepeda motor dan mobil.

4. Alat-alat elektronik

Kepemilikan alat elektronik juga digunakan sebagai indikator untuk mengetahui bagaimana keadaan perekonomian didalam keluarga responden, untuk lebih jelas maka dapat dilihat pada tabel 7.

Tabel 7. Kepemilikan alat elektronik

\begin{tabular}{ccc}
\hline Kategori & Frekuensi (org) & Persentase (\%) \\
\hline Semua ada & 7 & 23,33 \\
Hanya sebagian & 16 & 53,33 \\
Hanya sedikit & 7 & 23,33 \\
\hline Jumlah & 30 & $100 \%$ \\
\hline
\end{tabular}

Sumber : Analisis data primer 2021

Dari tabel 7. maka dapat diketahui bahwa dari 30 responden untuk kepemilikan alat elektronik ada 16 orang didalam kategori hanya sebagian (TV, VCD, Laptop/Komputer, Handphone, Mesin cuci, Kulkas, Kipas angin, Blender), sebanyak 7 orang yang di kategori alat elektronik hanya sedikit (TV, Kipas angin, Kulkas, Handpone), dan ada sebanyak 7 orang responden yang memiliki alat elektronik lengkap semua ada(AC, TV, VCD, Alat masak listrik, Laptop/Komputer, Telepon rumah, Mesin cuci, Kulkas, Kipas angin), dan memang masih sedikit karyawan yang memiliki AC didalam rumahnya.

5. Memiliki tabungan dan asuransi

Untuk mengetahui kondisi perekonomian keluarga kepemilikan tabungan atau asuransi juga digunakan dalam penelitian ini, untuk penjelasannya maka dapat dilihat pada tabel 8. 
Tabel 8. Memiliki tabungan atau asuransi

\begin{tabular}{ccc}
\hline Kategori & Frekuensi (orang) & Persentase (\%) \\
\hline Tabungan dan asuransi & 4 & 13,33 \\
Tabungan & 9 & 30,00 \\
Asuransi & 7 & 23,33 \\
Tidak ada & 10 & 33,33 \\
\hline Jumlah & 30 & $100 \%$
\end{tabular}

\section{Sumber :Analisis data primer 2021}

Dari tabel 8 diatas maka dapat kita ketahui bahwa banyak dari responden yang tidak memiliki tabungan atau asuransi sebanyak 10 orang, 9 orang yang memiliki tabungan, 7 orang yang memiliki asuransi dan hanya 4 orang yang memiliki keduanya.

6. Kepemilikan aset (Ternak, sawah/ladang, dan lainnya)

Kepemilikan aset adalah indikator yang digunakan pada penelitian ini untuk mengetahui bagaimana kondisi perekonomian didalam keluarga responden melalui aset yang dimiliki seperti ternak, sawah/ladang, dan aset lain yang dimiliki, untuk lebih jelas maka dapat kita lihat pada tabel 9.

Tabel 9. Kepemilikan aset

\begin{tabular}{ccc}
\hline Kategori & Frekuensi (orang) & Persentase (\%) \\
\hline $\begin{array}{c}\text { Memiliki sawah/ladang dan } \\
\text { ternak }\end{array}$ & 2 & 6,67 \\
Hanya memiliki sawah/ladang & 5 & 16,67 \\
Hanya memiliki ternak & 14 & 46,67 \\
Tidak memiliki & 9 & 30,00 \\
\hline Jumlah & 30 & $100 \%$
\end{tabular}

Sumber : Analisis data primer 2021

Dari tabel 9 diatas maka dapat diketahui bahwa dari 30 responden ada 14 orang yang hanya memiliki aset ternak (umumnya sapi dan kambing), 5 orang yang memiliki ladang/sawah (umumnya ladang singkong dan jagung), ada 2 orang responden yang memiliki ladang dan ternak, dan ada 9 orang yang tidak memiliki aset sama sekali.

Dari Kondisi perekonomian keluarga, kondisi rumah yang dihuni responden berbeda beda rata rata responden menghuni rumah yang disediakan oleh perusahaan dengan kondisi rumah biasa ditentukan oleh jabatan dan tingkat perekonomian masing masing keluarga.Pemenuhan gizi sangat dipengaruhi pendapatan keluarga.Kendaraan bermesin, semua responden memiliki sepeda motor tapi tidak semua memiliki mobil.Alat - alat elektronik, hanya 7 responden yang memiliki alat elektronik lengkap (AC, TV, VCD, Alat masak listrik, Laptop/Komputer, Telepon rumah, Mesin cuci, Kulkas, Kipas angin).Tabungan dan 
asuransi, hanya ada 4 orang responden yang memilikikeduanya.Aset lain (ternak, sawah/ladang), hanya 2 orang responden yang memiliki keduanya, maka dapat disimpulkan bahwa rata - rata kondisi keluarga wanita bekerja di PTPN IV Pabatu masuk kedalam kategori menengah kebawah (cukup sejahtera).

\section{KESIMPULAN}

1. Faktor yang berpengaruh nyata terhadap wanita bekerja sebagai tenaga kerja di perusahaan PTPN IV Pabatu adalah penghasilan pasangan, jumlah tanggungan dan mengembangkan diri. Penghasilan pasangan berpengaruh negatif, sedangkan jumlah tanggungan dan mengembangkan diri bertanda positif.

2. Kondisi perekonomian keluarga wanita bekerja di PTPN IV Pabatu masuk kedalam kategori cukup sejahtera

\section{DAFTAR PUSTAKA}

Sugiyono, 2016. Metode Penelitian Kuantitatif. Alfabeta, Bandung

Wantini dan kurniati, 2013. Faktor - faktor yang mempenaruhi motivasi wanita bekerja sebagai buruh pabrik garmen di Pt.Ameya Living Style Indonesia, Jurnal ekonomi syariah Indonesia Prodi Ekonomi Syariah Sekolah Tinggi Ilmu Agama Alma Ata, Vol: 3 No. 1.

Hasanah, Maktubatul, P. Edi Suswandi, and Duwi Yunitasari. 2019. "Analisis Faktor Yang Mempengaruhi Minat Tenaga Kerja Wanita Bekerja Di PTPN X Unit Industri Bobbin Kecamatan Arjasa Kabupaten Jember." E-Journal Ekonomi Bisnis Dan Akuntansi 6(1):57. doi: 10.19184/ejeba.v6i1.11077.

Putu, Desak, Eka Nilakusmawati, and Made Susilawati. 2012. "Studi Faktor-Faktor Yang Mempengaruhi Wanita Bekerja Di Kota Denpasar." Piramida 8(1):26-31.

S, Wahyu Nugraheni. 2012. "Peran Dan Potensi Wanita Dalam Pemenuhan Kebutuhan Ekonomi Keluarga Nelayan." Journal of Educational Social Studies 1(2). doi: 10.15294/jess.v1i2.739. 